\title{
The Tonal Representations of Violence in PG-13 Rated Cinema
}

\author{
Michael Guigliano ${ }^{1}$ and Daniel Olivo" ${ }^{1 \#}$ \\ ${ }^{1}$ Bergen County Technical High School Teterboro, NJ, USA \\ \#Advisor
}

\section{ABSTRACT}

Exposure to different tones of movie violence has been shown to affect viewers in different ways. Particularly, exposure to violence designed to evoke a comedic reaction may cause an overall desensitization to violence, more so than violence of a serious nature. There is a significant gap in current literature regarding analysis of the nature of different tones of movie violence. This study seeks to explore said gap, particularly with regards to PG-13 rated movies. Eight PG-13 rated films were randomly selected from 1984 to 2019 and through a mixed-method approach, were each subjected to a content analysis. All eight of the films contained at least one instance of comedic violence, but the presence of serious violence was significantly more prevalent. Instances of comedic violence were all supported through stylistic and theoretical indications of comedy. This study finds that some of the most highly viewed films engage in the practice of making violence humorous, which has been found to have a negative effect on viewers. Future research should apply the method developed for this study on a broader scale and to different genres of film.

\section{Literature Review}

Evidence tends to suggest that there are several harmful effects associated with the consumption of violent media (Anderson 161-178). Researcher Christina Yancey found that, while criminal aggression does not correlate with increased violent media exposure, frequent consumption can result in people being more aggressive in an "annoying" manner (Yancey \& Savage 772-791). Another study found that exposure to media violence can result in an increase in pro-violence attitude, the idea that resorting to violence is the way to solve conflicts (Funk et al. 23-39). Additionally, some believe that an increase in the consumption of violent media can result in a decrease in empathy (Strasberg 54-102). However, this is a highly disputed notion, and many studies suggest that a decrease in empathy is not nearly as prevalent as the other side-effects (Funk et al. 23-39). The aforementioned effects may be especially heightened by the constant viewing of violent media in adolescence (Bleakley et al. 73-79).

\section{The Effects of Violence Tonally}

The previously mentioned effects are repercussions of consuming all the different tones of violence, but they can be heightened by exposure to specifically comedic violence (McArthur 120-124). Violence in films can be portrayed as lighthearted to make incredibly dangerous acts seem less violent (McArthur 120-124). The way in which violence can be toned down is by rarely portraying the negative consequences of it as well as using it for comedic effect (McIntosh et al., 345-360). Through an extensive look at pre-existing literature, Steven J. Kirsh found that violence of a comedic nature can have especially harmful effects, particularly on children (547-557). When the tone of violence is lighthearted, it can not only make the harmful effects of violence seem less impactful, but also make them seem funny (McIntosh et al., 345-360). This form of violence is otherwise known as slapstick comedy which is physical punishment that is painful only for comical purposes and never truly life threatening (Weitz \& Jenness 127-128). 
Additionally, observing slapstick comedy can result in desensitization to violence more quickly than observing traditional forms of violence (Kirsh 547-557). Desensitization is the idea that one's emotional response to negative stimuli is diminished after the frequent observation of such stimuli (Fanti 179-187). Humor disengages the human mind from very real and violent consequences, thus blocking out one's compassion for those negative events (Potthast 1-12). These sources show how the frequent observation comedic violence can have detrimental effects on viewers.

\section{The Prevalence of Movie Violence}

The aforementioned side-effects of violence, both generally and from a comedic tone, may not be alarming on the surface level, but when looking at how much violence there is in film, they become much more meaningful. It's estimated that approximately $91 \%$ of all on-screen media contains some form of violence (Worth et al., 306-312). The amount of violence in film has also been on the rise. A recent study states that, since the introduction of the PG-13 rating, violence in film has been continually increasing since that initial date (Bushman et al., 1014-1018). This coincides with another study that discusses how violence in PG-13 rated movies has tripled since their inception in 1984 (Wilson \& Hudson Gun Violence in PG-13 Films). This shows that there have been numerous studies that document the amount of violence present in media. It has also been established that there are negative effects associated with consuming violence of different tones and that the amount of violence has been increasing in movies. However, no study has specified the tonal nature of the said prevalent and increasing violence in films, presenting a significant gap in the current understanding of this topic.

\section{Research on Tone of Movie Violence}

As previously mentioned, little research has been done on the different tones of violence in films. In a 2000 study, researchers Kimberly Thompson and Fumie Yokota mentioned the tones of violence in G-rated animated films specifically targeted at kids (Yokota \& Thompson 2716-2718). In this study, the tones of violence were not the primary inquiry as they were used to help aid the discussion of violence overall. The focus of the study was to capture the overall landscape of violence in animated films and tone of violence was a small piece of that. There have been no studies that have exclusively analyzed the different tones of violence in films.

\section{The History of the MPA's PG-13 Rating.}

The PG-13 film rating was established as a compromise between the two existing ratings, R and PG (Sullivan $P G-13$ Turns 30). This was done because of the film Indiana Jones and the Temple of Doom which was too violent to be rated PG but not violent enough to warrant an R rating (Parker, How 'The Temple of Doom' Changed the MPAA Ratings System). The first PG-13 rated film was Red Dawn but since then, over four thousand films have been issued the rating, making up approximately $16 \%$ of the total number of films rated by the MPA (TV Week How Many Movies Have Been Rated?). This shows that the PG-13 rating is not necessarily the most assigned. However, despite making up only a small portion of the number of films that are released in theatres every year, they are some of the most viewed films in the industry (Follows Which MPAA Rating Earns the Most?). Many filmmakers view the PG-13 rating for movies as the most appealing to audiences, making them the most financially rewarding (Terry et al. 137-147). This was clearly represented in the year 2015, where PG-13 films were responsible for 51\% of domestic box office revenue (Markey \& Ferguson 395-403). This means that PG-13 rated movies tend to be the rating of film people watch the most, thus affecting the most viewers.

There has not been a study yet that has even acknowledged comedic violence in the most watched type of film, those that are PG-13. While evidence suggests that comedic violence may negatively impact younger kids and G-rated films lend themselves more to being seen by them, the PG-13 rating is also attractive to adolescents (Leone 
\& Osborn 86-87). The rating acts as a Trojan Horse, appealing to younger audiences due to the films being seen as “edgy" (Leone \& Osborn 86-87). In other words, PG-13 rated films, while not directly marketed to adolescents, are seen as being attractive by that audience. PG-13 rated films are the most popular rating of film (Markey \& Ferguson 395-403) and they are heavily enjoyed by the market most vulnerable to negative effects of exposure to violence (Leone \& Osborn 86-87). In conclusion, the existing literature shows that a content analysis of the different tones of violence in PG-13 rated cinema would be a logical next step in this field of study.

\section{Methods}

This study seeks to explore how violence has been tonally represented in PG-13 rated films. The selected films were subjected to a mixed-method content analysis to determine the prevalence of different tones of violence, specifically, tones of comedic and serious violence. The mixed-method approach worked best for this study since it not only allowed for the amounts of comedic and serious violence to be quantitatively compared, but also permitted qualitative justifications regarding the decisions to code an instance of violence as either serious or comedic. Violence was defined as an intentional or accidental act where an aggressor makes some physical contact that has potential to inflict injury or harm (Yokota \& Thompson, 2716-2718). In the definition, physical contact can be with anything and includes self-harm. The definition of violence used in this study reflects Yokota and Thompson's with a personal addition of unintentional acts of violence. An example of intentional violence would be someone throwing a punch at another person whereas an example of unintentional violence would be someone tripping on something and hurting themselves. However, in order for the unintentional act of violence to have been considered, there needed to have been some physical change in the surrounding environment. For example, simple tasks such as driving could apply to the definition since they could potentially harm someone. For instances like these to count, there needed to be some physical, destructive event on a character or the surrounding world. If in the aforementioned driving example, an aggressor accidentally drives into something, the incident would be considered an instance of violence.

Violence off screen did not count according to this definition. An example of this would be the audience hearing gun fire but not seeing it happen. This is because the visual cues of comedy could not be seen in the incident, so there would be no way of knowing if the violence is comedic or not. This would mean that the definition used did not account for the effects and aftermath of violence. For instance, if someone has an injury from a previous fight or if there is a destroyed building from a bomb going off, neither would count as being violence according to the definition. The instance needed to occur visually, so the effects of an instance of violence did not count. The same would apply to violence where the audience sees the incident happening, but audio is not present. Instances that could be considered violent only counted if there was some visual and auditory representation of it. Violence was measured using a measurement created in Yokota and Thompson's paper known as an "instance of violence" (Yokota \& Thompson 2716-2718). This is an uninterrupted display of violence. The instance of violence would begin at the first identified physical attack. If the film cut to another scene or if the exerting of physical force stopped, that instance of violence would be considered over. If the film cut back to a previous instance of violence, despite being the same physical aggressors, it would be considered a separate incident. An aggressor can try to inflict harm on multiple subjects, and it can still be counted as the same instance of violence.

\section{Coding}

The codes used were "comedic" and "serious". Unless the violence was made out to be comedic, it would be considered serious since violence is inherently serious (McArthur 120-124). In order for an instance to be considered comedic, the violence itself would need to be humorous, so the instance did not count if a character made a joke or quip before or after the actual violence that would have made an otherwise serious instance comedic. A shout or visceral reaction can contribute to the tone but not a one-liner that follows or precedes the incident. The evidence used 
to justify whether something was comedic or serious was through the usage of two categories: "stylistic" and "theoretical." These two categories were used since they each encompass techniques and methods filmmakers use to communicate comedy to the audience (Renée Cinematic Techniques to Determine Tone). Within the category of stylistic indicators, there are two sub-categories: auditory and visual indications of comedy. The visual description of the sequence would be composed of lighting-- the way shadows and light are cast in the scene--, set design-- the characteristics of the props and sets--, and color correction-- how the scene's tones of colors are changed in postproduction (StudioBinder Visual Tone). Additionally, the usage of different shots can influence tone as well. When a film rapidly changes between two different types of shots, it can indicate comedy. For instance, if a wide shot (a camera position that shows the full environment of a scene) rapidly changes to a close-up (a camera position where the focus of the scene is shown in greater detail) comedy is oftentimes indicated (StudioBinder Visual Tone). Additionally, the presence of violence in the background of the shot can indicate comedy (EveryFrameAPainting Edgar Wright Visual Comedy). For example, in a scene from the film Scott Pilgrim vs. the World, the title character, Scott, jumps through a window in the background while his roommate is talking to someone in the foreground. The utilization of action occurring in the background makes the instance humorous (EveryFrameAPainting Edgar Wright Visual Comedy). Auditory cues would be through music-- the nature of any composed arrangement being played over a scene-- and sound effects-- the nature of the sound created because of an action being performed (Renée Cinematic Techniques to Determine Tone). Additionally, the actual presence of music can determine tone. If music suddenly stops, it can indicate comedy (Renée Cinematic Techniques to Determine Tone).

For the theoretical category, I applied the content of the instance of violence to different pre-existing theories. Within the theoretical category, three different principal theories, which are believed to explain why people view things as being comedic (Borgella What Makes Things Funny), were considered. The most primitive of these theories is the superiority theory. This theory was developed by ancient Greek philosophers like Aristotle and Socrates and states that humor is derived from the mocking of foolish actions of others (Borgella What Makes Things Funny). When dramatic irony was present or when a character did something foolish, the instance would be marked under superiority theory. The second of these theories is the incongruity theory. Initially adopted by philosophers such as James Beattie and Immanuel Kant, this theory holds the idea that unexpectedness can create humor (Lintott 347-354). The third theory of humor applied was the relief theory. This is when there is a serious buildup of tension that ultimately equates to a non-serious outcome (Morreall 1-18). This theory was made popular by psychologist Sigmund Freud. While all three of these theories were originally developed to be the sole explanation of why things are funny, it is widely accepted that they may not capture all types of humor (Lintott 347-354). Therefore, it would be necessary to utilize the three basic theories of humor, rather than just one of them. This also means that a comedic instance of violence may apply to all three of these theories or just one. In order for an instance of violence to be considered comedic, a stylistic and theoretical indication of humor must have been present and not just one or the other. This is because an instance of violence that is clearly designed to be serious may apply to a single stylistic or theoretical indication, so by requiring both, the method further reduces the possibility of miscoding.

\section{Film Selection}

The movie selection process was based on showing diversity in release years and overall popularity. PG-13 films were first introduced in 1984 (Sullivan PG-13 Turns 30). Hence, films were looked at from then until 2019. The year 2020 was not included in this research study due to the coronavirus pandemic and most films being either pushed to a later release date or released digitally (Pallotta Blockbusters Pushed Back). Therefore, four, nine-year spans of time were created to classify films. The box-office gross, according to BoxOfficeMojo.com, was then looked at to determine the ten highest grossing films from each nine-year span. To account for inflation, the grosses were all adjusted to the value of the 2020 American dollar using TheInflationCalculator.com.

The box office gross was the way of determining how many people had seen each film and the movie's overall popularity. Once each list of ten films was created, two from each nine-year span were randomly selected. Out 
of the total of forty films, eight were selected to be watched. The eight that were randomly selected were, The Color Purple (1985), Indiana Jones and the Last Crusade (1989), The Sixth Sense (1999), Lord of the Rings: The Fellowship of the Ring (2001), Spider-Man (2002), The Dark Knight (2008), Jurassic World (2015), and Star Wars Episode VIII: The Last Jedi (2017).

\section{Results, Products, And Findings}

Through the use of Google Sheets, time stamps and brief descriptions of each instance were recorded. Additionally, it was noted if each instance was either serious or comedic. If the violence was deemed to be comedic, there would be a justification for that choice. The justifications include a stylistic indication of violence--visual, auditory, or both-and a theoretical justification--incongruity, superiority, relief, or any combination of the three. Then there was a written explanation of how that instance fit into the stylistic and theoretical subcategories it was assigned. The justification for something being serious was simply that it would not fit into any of the subcategories for comedic violence so that was not recorded.

\section{Star Wars Episode VIII: The Last Jedi}

This film showed a significant amount of comedic violence when compared to the other seven films. The film had 107 total instances of violence throughout its 2 hour and 32-minute runtime. 18 of these instances were considered to be comedic, meaning that approximately $16.82 \%$ of the violence in the film was comedic (See appendix table 1). This also means that in every hour of the film, there were 7.11 instances of comedic violence. All of these comedic instances were supported by either the theory of incongruity or the theory of superiority. There were no comedic instances of violence that could be justified using the relief theory of humor. Regarding visual indications of comedic violence, visual humor was derived from the quick changes in different shots.

\begin{tabular}{|l|l|}
\hline Time & Justification \\
\hline$(12: 29-12: 55)$ & $\begin{array}{l}\text { While the blow is dealt, the shot quickly changes from a } \\
\text { wide-shot of the scene to a closeup on General Hux }\end{array}$ \\
\hline
\end{tabular}

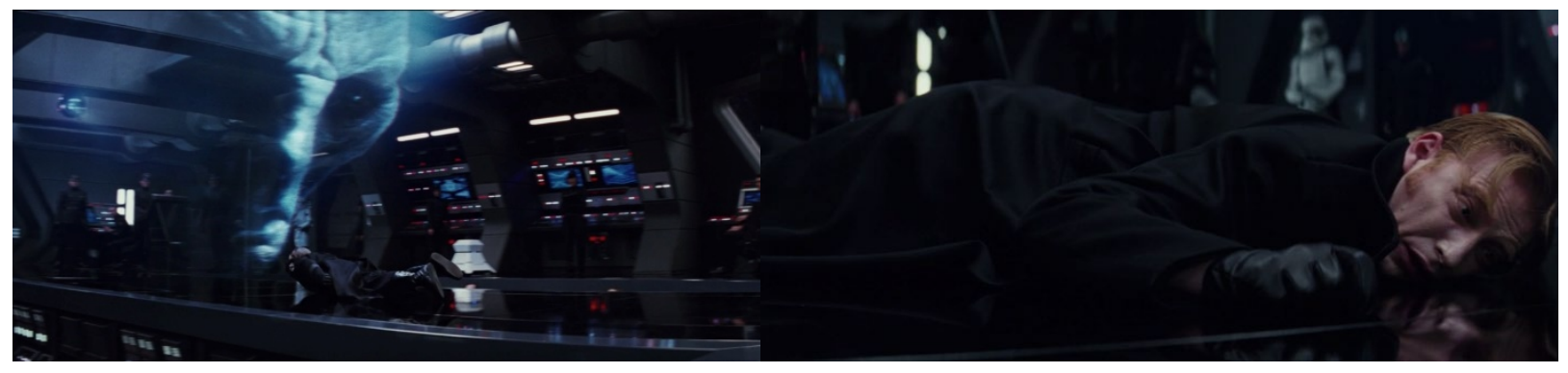

This technique was seen often throughout the film and was one of the many ways the filmmakers communicated to the audience that the instance of violence was intended to be humorous. Additionally, comedic violence was communicated through showing the violence occur in the background of the shot. Auditory indicators of comedy were often portrayed through the use of sound from within the scene (foley). Characters would often make lighthearted sounds that inspired the instance's comedic tone. Such auditory indications of comedy oftentimes coincided with the presence of superiority theory. These are the most common stylistic and theoretical indicators of comedy in the film. 


\section{The Sixth Sense}

Being a horror film, The Sixth Sense naturally lacked a significantly high count of violence, both serious and comedic. The film had only 9 instances of violence throughout its 1 hour 50-minute runtime. Two of these instances were classified as being comedic while the other 7 were considered serious (See appendix table 8 ). This means that $22.22 \%$ of the film's violence was comedic. While this was the highest percentage of any of the eight films, it only had 1.09 instances of comedic violence per hour, showing the film lacked a significant amount given its runtime.

\begin{tabular}{|l|l|}
\hline$(1: 29: 00-1: 29: 30)$ & $\begin{array}{l}\text { The scene is very brightly lit which gives it a } \\
\text { lighthearted tone }\end{array}$ \\
\hline
\end{tabular}

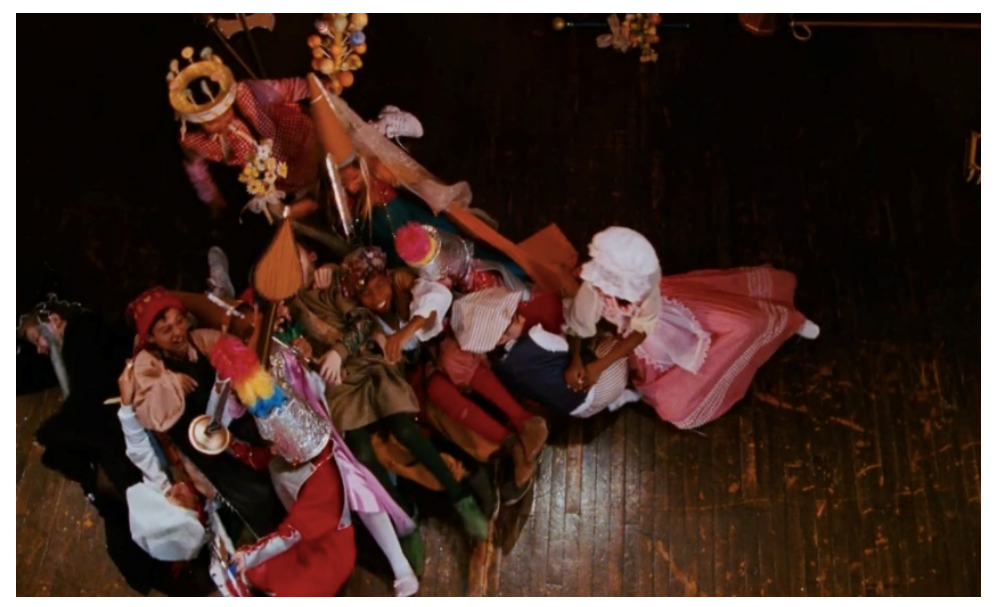

In one instance, visual comedy was indicated through the use of bright lighting. This indicated to the audience that the scene was lighthearted and fun (StudioBinder Visual Tone). Throughout all eight films, this was the only instance in which bright lighting contributed to comedic effect.

\section{Indiana Jones and the Last Crusade.}

This film had one of the higher counts of instances of violence. While not as high as Star Wars Episode VIII: The Last Jedi's 107 instances, Indiana Jones and the Last Crusade had 82. This film had 12 instances of comedic violence and 70 instances of serious violence (See appendix table 2). This means that roughly $14.63 \%$ of the film's violence had a comedic tone which equates to there being 5.63 instances of slapstick violence per hour. The biggest difference with regards to the comedic violence justifications was that the other films lacked any instances that applied to relief theory, whereas this film had one.

\begin{tabular}{|l|l|}
\hline$(7: 30-7: 36)$ & $\begin{array}{l}\text { The rhino was extremely close to hitting Indiana but } \\
\text { missed ever so slightly }\end{array}$ \\
\hline
\end{tabular}

In this scene, Indiana Jones is dodging a rhinoceros but comes extremely close to being hit. This would apply under the comedic theory of relief since there is buildup which ultimately amounts to nothing bad happening to any characters (Morreall 1-18). For auditory cues, oftentimes the music would stop when the comedic instance of violence was occurring. This was one of the most prominent ways in which the film auditorily indicated comedic violence and was a major difference between this film and the others. 


\section{Jurassic World}

This film had a relatively low count of both serious and comedic violence. Throughout its runtime of 2 hours and 5 minutes, there were 46 instances of violence and only 3 of them were considered to be comedic while 43 were serious (See appendix table 5). This means that comedic violence only comprised approximately $6.5 \%$ of the total violence in the film. This equates to there only being 1.44 instances of comedic violence per hour. Two of these instances occurred immediately after each other and were only separated by a few seconds. Those two instances both applied to the theory of superiority and the theory of incongruity. The first of the two utilized the visual medium to communicate comedy by having the shot change rapidly from a close-up to a wide-shot. The second utilized sound effects from within the scene. Later in the film, the only other instance of comedic violence occurs. This instance applied to the theory of incongruity and was visually communicated by having the violence take place in the background.

\section{The Lord of the Rings: The Fellowship of the Ring}

This film had 70 instances of violence throughout its 2 hour and 58-minute runtime. Only four instances were considered to be comedic and were heavily concentrated at the beginning of the film (See appendix table 4). However, there were 66 instances of serious violence. This means only about 5.5\% of violence in the film had a comedic tone, meaning that there were only about 1.35 instances of comedic violence per hour.

In this instance of comedic violence, the film's main character, Frodo, is suddenly tackled by his friend, Pip. This instance and several other instances of comedic violence throughout the movie utilized music differently than other films. When the film used auditory indicators of comedy, rather than the presence of music influencing comedic tone, the melodic nature of the music itself did. In Indiana Jones and the Last Crusade, the lack and sudden stops in music created a comedic effect but, in this film, the music itself dictated the tone of violence. This form of auditory indication occurred twice in the film. All comedic instances of violence were supported by at least incongruity theory. Not once was there an instance that was backed by only the theory of superiority as it was always accompanied by the incongruity theory.

\section{The Dark Knight}

This film had the least amount of comedic violence out of all of the eight films, but the largest amount of serious violence. There was only one instance of comedic violence and 103 instances of serious violence with a total of 104 instances of violence (See appendix table 7 ). This means that $0.96 \%$ of the total violence in the film was comedic and that there was an instance of comedic violence 0.39 times every hour. The one instance of comedic violence featured two young kids pretending to shoot handguns with their fingers, which surprisingly caused actual explosions to go off. This was not actually caused by them, rather Batman firing his weapon. This instance applied to the theory of incongruity since the audience would not expect an actual explosion to be caused by two kids playing. This was accompanied by an auditory indication of comedy since the kids were making comical noises to represent gunfire.

\section{Spider-Man}

This film had 54 instances of violence and only 2 of them were comedic while 52 of them were serious (Table 6). This means that only about $3.7 \%$ of the violence in the film was comedic, resulting in 0.99 instances of comedic violence per hour. These two instances of violence were both supported by the theory of superiority but one of them was 
supported by relief theory. In this instance, Peter Parker is practicing his web-slinging abilities and accidentally shoots a lamp that nearly hits him in the head.

$(33: 20-33: 25)$

Peter comes very close to injuring himself when

throwing the lamp

This instance also applied to superiority theory since Peter Parker made a mistake. Both instances of comedic violence in the film used a visual indication of comedy but in two different ways. One uses the rapid change from a close-up to a wide shot, and the other has violence occur in the background.

\section{The Color Purple}

Being a drama, this film had a significantly lower count of violence throughout its 2 hour and 34-minute runtime. The film had 28 total instances of violence with 4 being comedic, and the remaining 24 being serious (See appendix table 3 ). This means that roughly $14.29 \%$ of the violence in the film was comedic and that there were approximately 1.56 instances of comedic violence per hour. Comedic violence was supported most commonly through the use of visual comedy. The most common visual indicator of comedy was the action not happening in the foreground of the shot.

$(1: 01: 44-1: 01: 45)$

Someone falls through the roof of the shed in the background of the shot

The most common auditory indication of comedic violence was through the use of lighthearted and joyous music. This use of auditory indicators of comedy was similar to that of Lord of the Rings: The Fellowship of the Ring. Each comedic instance of violence was supported by both the theory of incongruity and the theory of superiority.

\section{Trends Seen in the Eight Films}

Throughout all eight films, violence was more often portrayed in a serious manner. There were very few comedic instances of violence that applied to the relief theory of humor and the majority of them applied to either incongruity theory or superiority theory. More often than not, the instance of violence applied to multiple theories and the most common pairing was incongruity theory with superiority theory. Additionally, visual indicators such as the violence being in the background of the scene and rapid changes in shot composition were common among the eight films. One relation between the theoretical and stylistic indicators was incongruity theory often corresponding with rapid shot changes, showing that the two might be closely tied. There was significant diversity with auditory indications of comedy as the films used music in different ways. Films such as The Lord of the Rings: The Fellowship of the Ring and The Color Purple both utilized lighthearted music to imply comedy whereas the film Indiana Jones and The Last Crusade utilized the abrupt stoppage of music to imply it.

\section{Conclusion}

This data shows that films shown to large audiences engage in the practice of presenting violence in a comical way. The presence of comedic violence is significantly less prevalent than that of serious violence; however, there is still a noticeable amount of it. The instances of comedic violence that were detected are heavily supported by theoretical and stylistic implications of comedy. In reality, the comical actions often portrayed in the films can have severe repercussions. As previously mentioned, exposure to such content desensitizes viewers to the very real and harmful effects of violence (Kirsh 547-557). Additionally, humorous elements in violent instances can signal to audiences that 
serious acts are funny and to be taken lightly (Kirsh 547-557). In conclusion, this study reveals just how popular the use of comedic violence is in highly viewed cinema, and considering the harmful effects associated with exposure to such material, there should be cause for concern. Films such as Star Wars Episode VIII: The Last Jedi and Indiana Jones and the Last Crusade may be especially harmful to younger audiences-- who are more prone to desensitization (Kirsh 547-557) -- due to the sheer amount of comedic violence, supported by the theories of incongruity and superiority as well as visual and auditory indications of comedy.

This research fills a significant gap in the current body of knowledge. The method used for this research is newly developed and the tone of violence in PG-13 rated films has not been acknowledged by pre-existing literature. Although the tone of violence in solely animated films has been studied, it was in a more quantitative way than this study (Yokota \& Thompson 2716-2720). Additionally, the use of tone in that study was primarily for purposes of sorting data; exploration of tones of violence was not the primary focus of it. No other studies take into account the different tones of violence in particular films. This paper also includes accidental violence which has not been accounted for in other studies. Overall, this study fills the gap in current research by accounting for different tones of violence in films through a mixed-method approach.

\section{Limitations}

There are several potential limitations to this study. A significant limitation is that the content analysis was completed by a single person, leaving room for human error and subjectivity. The subjectivity is partly combated by some of the stylistic justifications which are difficult to dispute; for example, the presence of music is not very interpretive: an instance of violence either does or does not have it. However, the theoretical justifications are much more subjective, particularly because each individual may have a different interpretation of the three theories. If the content analysis had been conducted by multiple coders, the study would have been more objective, as consulting regarding different coding decisions could be done. There are also limitations with the sampling method itself. The eight films that had been randomly selected may not have been entirely representative of PG-13 rated films as a whole. Something that was not accounted for in the sampling phase was the potential for films that occurred in a similar time frame to all appear. Despite selecting two from each nine-year span, it was possible that three or four movies could be selected in the same five-year span. This ultimately was the case as The Sixth Sense (1999), Lord of the Rings: Return of the King (2001), and Spider-Man (2002) were all selected. In a larger research study, a better method of sampling would be to select one movie from every year. This would be more representative of the PG-13 film landscape. Additionally, the number of films looked at was only eight. This sample size does not adequately represent the more than four thousand films that have been rated PG-13 (TV Week How Many Movies Have Been Rated?). More specific and accurate claims can be made about the PG-13 film landscape with a larger sample size. Regardless of limitations, the data shows that there is still a significant amount of violence designed for comedic effect in PG-13 rated films.

\section{Future Directions}

The methodology developed for this study can be applied to any different genre or rating of film. Since much evidence suggests that comedic violence most negatively affects children (Kirsh 547-557), a study could be done analyzing different tones of violence in G-rated and PG-rated films as they are widely viewed by adolescents (Yokota \& Thompson 2716-2718). While this was looked at by researchers Fumie Yokota and Kimberly Thompson, the tones of violence in these films should be investigated further, specifically using the methodology developed for this study. Additionally, this study only accounted for comedic and serious tones. Future research should also look to add a neutral tone code, as this was classified as "serious" when detected in this study. Another future direction would be expanding the scope of the study. Now that a reliable method has been established, future research could apply it on 
a broader scale to include more films and perform a more encompassing research study. In short, there are numerous directions this research could take.

\section{References}

Anderson, Craig A. "Effects of Violent Movies and Trait Hostility on Hostile Feelings and Aggressive Thoughts." Aggressive Behavior, vol. 23, no. 3, 1997, pp. 161-178. Crossref, doi:10.1002/(SICI)1098-2337(1997)23:33.0.CO;2-P.

Bleakley, Amy, et al. "Trends of Sexual and Violent Content by Gender in Top-Grossing U.S. Films, 1950-2006." Journal of Adolescent Health, vol. 51, no. 1, 2012, pp. 73-79. Crossref, doi:10.1016/j.jadohealth.2012.02.006.

Borgella, Alex. "Science Deconstructs Humor: What Makes Some Things Funny?" The Conversation, 2 Nov. 2016, theconversation.com/science-deconstructs-humor-what-makes-some-thingsfunny-64414.

BoxOfficeMojo. “BoxOfficeMojo.Com.” Box Office Mojo, Mar. 2021, www.boxofficemojo.com.

Bushman, B. J., et al. "Gun Violence Trends in Movies." PEDIATRICS, vol. 132, no. 6, 2013, pp. 1014-1018. Crossref, doi:10.1542/peds.2013-1600.

"Edgar Wright - How to Do Visual Comedy." YouTube, uploaded by Every Frame a Painting, 27 May 2014, www.youtube.com/watch?v=3FOzD4Sfgag.

Fanti, Kostas A., et al. "Desensitization To Media Violence Over A Short Period Of Time." Aggressive Behavior 35.2 (2009): 179-187. Criminal Justice Abstracts with Full Text. Web. 20 Apr. 2016.

Ferguson, Christopher J., and Patrick Markey. "PG-13 Rated Movie Violence and Societal Violence: Is There a Link?” Psychiatric Quarterly, vol. 90, no. 2, 2019, pp. 395-403. Crossref, doi:10.1007/s11126-018-9615-2.

Follows, Stephen. "Which MPAA Rating Earns the Most Money?" Stephen Follows, 22 Nov. 2019, stephenfollows.com/which-mpaa-rating-earns-the-most-money/.

Funk, Jeanne B., et al. "Violence Exposure in Real-Life, Video Games, Television, Movies, and The Internet: Is There Desensitization?” Journal of Adolescence, vol. 27, no. 1, 2004, pp. 23-39. Crossref, doi:10.1016/j.adolescence.2003.10.005.

Jenness, Joe, and Eric Weitz. "The Cambridge Introduction to Comedy, Eric Weitz (2009).”

Comedy Studies, vol. 1, no. 1, 2010, pp. 127-128. Crossref, doi:10.1386/cost.1.1.127.

Kirsh, Steven J. "Cartoon Violence and Aggression in Youth." Aggression and Violent Behavior, vol. 11, no. 6, 2006, pp. 547-557. Crossref, doi:10.1016/j.avb.2005.10.002.

Leone, Ron, and Lynn Osborn. "Hollywood's Triumph and Parents' Loss: An Examination of the PG-13 Rating." Popular Communication, vol. 2, no. 2, 2004, pp. 85-101., doi:10.1207/s15405710pc0202_2.

Lintott, Sheila. "Superiority in Humor Theory." The Journal of Aesthetics and Art Criticism, vol. 74, no. 4, 2016, pp. 347-358. Crossref, doi:10.1111/jaac.12321.

McArthur, D. "Violence and Its Injury Consequences in American Movies: A Public Health Perspective." Journal of the International Society for Child and Adolescent Injury Prevention, vol. 6, no. 2, 2000, pp. 120-124. Crossref, doi:10.1136/ip.6.2.120.

McIntosh, William D., et al. "What's So Funny About a Poke in the Eye? The Prevalence of Violence in Comedy Films and Its Relation to Social and Economic Threat in the United States, 19512000." Mass Communication and Society, vol. 6, no. 4, 2003, pp. 345-360. Crossref, doi:10.1207/s15327825mcs0604_1.

Morreall, John. "Enjoying Incongruity." Humor - International Journal of Humor Research, vol. 
2, no. 1, 1989, pp. 1-18. Crossref, doi:10.1515/humr.1989.2.1.1.

Parker, Ryan. "'Indiana Jones and the Temple of Doom' Changed the MPAA Ratings System."

The Hollywood Reporter, 23 May 2017, www.hollywoodreporter.com/heat-vision/indiana-jones-templedoom-changed-mpaa-ratings-system-999618.

Pallotta, Frank. "The Biggest Movies That Have Been Delayed, and When You Can Expect to

See Them Now." CNN, 26 Sept. 2020, edition.cnn.com/2020/09/26/media/delayed-movies-coronavirus2020/index.html.

Potthast, Adam. "The Ethics of Slapstick Humor." 29 Apr. 2016, pp. 1-12 cte.ku.edu/sites/cte.drupal.ku.edu/files/docs/CTEprograms/CHRP/Portfolios/Potthast/paperE.pdf.

Renée, V. "Which Cinematic Techniques Can You Use to Change the Tone of a Scene?" No Film

School, 18 Feb. 2017, nofilmschool.com/2017/02/which-cinematic-techniques-can-you-use-change-tonescene.

Savage, Joanne, and Christina Yancey. "The Effects of Media Violence Exposure On Criminal Aggression." Criminal Justice and Behavior, vol. 35, no. 6, 2008, pp. 772-791. Crossref, doi:10.1177/0093854808316487.

Shore, T. "Why blaming movie violence for inexplicable tragedy is a mistake" The Guardian.

Aug. 2012 https://www.theguardian.com/film/filmblog/2012/aug/03/movie-violence-mass-shootings.741

Strasburger, Victor. "Adolescents, Media Portrayals Of." Encyclopedia of Children, Adolescents, and the Media, Mar. 2004, pp. 54-102 doi:10.4135/9781412952606.n3.

StudioBinder. "Film Tone - Filmmaking Techniques for Directors: Ep1." YouTube, uploaded by StudioBinder, 22 May 2018, www.youtube.com/watch?v=Tkbto1oLAnE.

Sullivan, Kevin P. "PG-13 Turns 30: Looking Back At The Two Movies That Made The Rating Necessary." MTV News, 1 July 2014 www.mtv.com/news/1859122/pg-13-rating-anniversary/.

Terry, Neil, et al. "The Determinants of Domestic Box Office Performance in the Motion Picture Industry." Southwestern Economic Review, 2005, pp. 137-148, www.ser.tcu.edu/2005/SER2005\%20Terry\%20Butler\%20DeArmond\%20137-148.pdf.

TVWeek "How Many Movies Have Been Rated R, PG, PG-13, G and X Over the Past 50 Years?" TVWeek, www.tvweek.com/tvbizwire/2018/10/the-mpaa-movie-rating-system-turns-50-and-theorganization-reveals-just-how-many-movies-have-been-rated-r-pg-pg-13-g-and-x/.

Wilson, Jacque, and William Hudson. "Gun Violence in PG-13 Movies Has Tripled." CNN, Cable News Network, 11 Nov. 2013, www.cnn.com/2013/11/11/health/gun-violencemovies/index.html\#: :text=Since 1950, violence in films has more than doubled, the films in more recent years.

Worth, Keilah A et al. "Exposure of US adolescents to extremely violent movies." Pediatrics vol. 122.2 2008, pp. 306-312. doi:10.1542/peds.2007-1096

Yokota, Fumie, and Kimberly Thompson. "Violence in G-Rated Animated Films." JAMA, vol. 283, no. 20, 2000, pp. 2716-2720. Crossref, doi:10.1001/jama.283.20.2716. 